\title{
SEPARATION OF PRODUCTS FROM MILD COAL GASIFICATION PROCESSES
}

\author{
P. Henrik Wallman
}

September 11, 1991

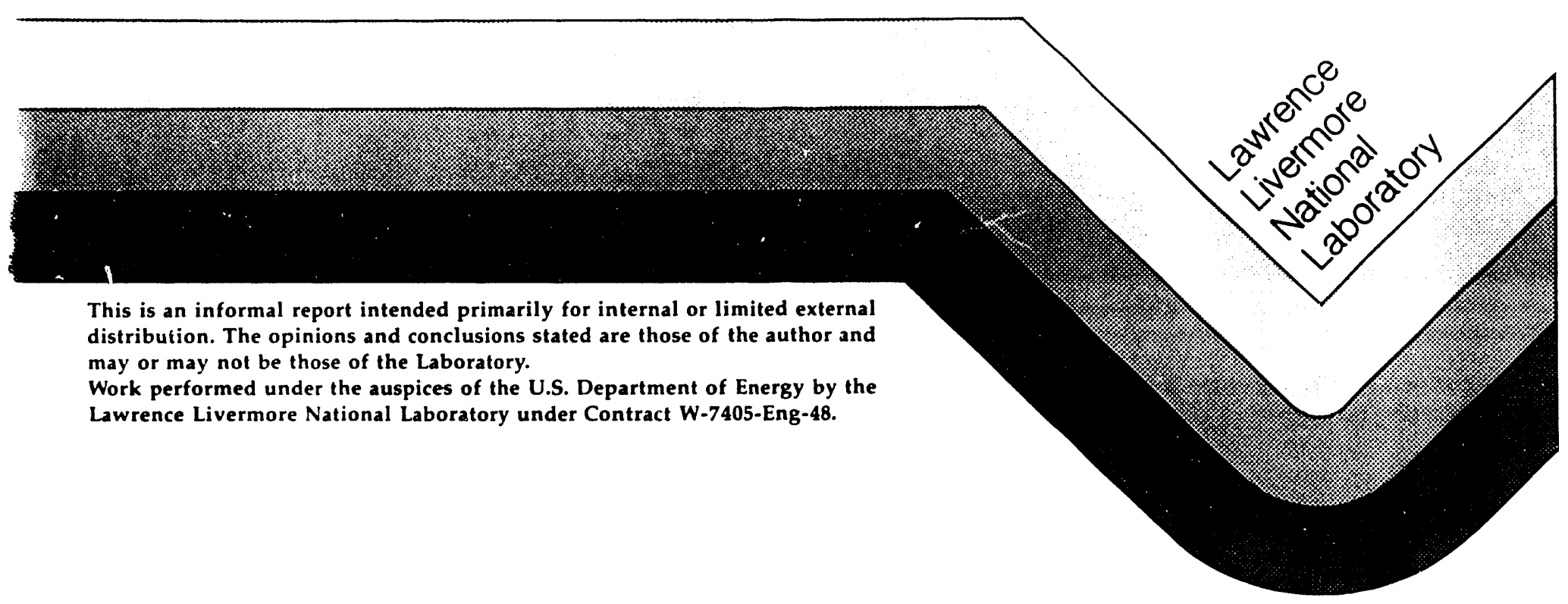




\section{DISCLAIMER}

This document was prepared as an acccount of work sponsored by an agency of the United States Covernment. Neither the United States Government nor the University of California nor any of their employees, makes any wirrunty. express or implied, or assumes any legal liability or responsibility for the accuracy, completeness, or usefulness of any' information, apparatus, product, or process disclosed, or represents that its use would not infringe privately own rights. Reference herein to any specific commercial products, process, or service by trade name, trademark, manufacturer, or otherwise, does not necessarily constitute or imply its endorsement, recommendation, or favoring by the United States Government or the University of California. The views and opinions of authors expressed herein do not necessarily state or reflect those of the United States Government or the University of California, and shall not be used for advertising or product endorsement purposes.

This report has been reproduced directly from the best available copy.

Available to DOE and DOE contractors from the Office of Scientific and Technical Information P.O. Box 62, Oak Ridge, TN 37831

Prices available from (615) 576-8401, FTS 626-8401

Available to the public from the National Technical Information Service

U.S. Department of Commerce 5285 Port Royal Rd. Springfield, VA 22161 


\title{
Separation of Products from Mild Coal Gasification Processes
}

\author{
by \\ UCRL-ID--108327 \\ P. Henrik Wallman \\ Lawrence Livermore National Laboratory \\ DE92 000092 \\ Livermore, California 94550
}

\begin{abstract}
The primary mild coal gasification product mixture containing noncondensible gas, highboiling hydrocarbon vapors and entrained fines is difficult to process into the desired pure products: gas, liquids, and dry solids. This challenge for mild coal gasification process development has been studied by surveying the technical literature for suitable separations processes and for similar issues in related processes.
\end{abstract}

The choice for a first-stage solids separation step is standard cyclones, arranged in parallel trains for large-volume applications in order to take advantage of the higher separation efficiency of smaller cyclones. However, mild gasification pilot-plant data show entrainment of ultrafine particles for which standard cyclones have poor separation efficiency. A hot secondary solids separation step is needed for the ultrafine entrainment in order to protect the liquid product from excessive amounts of contaminating solids. The secondary solids separation step is similar to many high-temperature flue-gas applications with an important complicating condition: Mild gasifier vapors form coke on surfaces in contact with the vapors. Plugging of the filter medium by coke deposition is concluded to be the main product separation problem for mild gasification. Three approaches to solution of this problem are discussed in the order of preference: (1) a barrier filter medium made of a perforated foil that is easy to regenerate, (2) a high-efficiency cyclone coupled with recycle of a solids-containing tar fraction for coking/cracking in the gasifier, and (3) a granular moving bed filter with regeneration of the bed material.

The condensation of oil vapors diluted by noncondensible gas is analyzed them.odynamically, and the conclusion is that existing commercial oil fractionator designs are adequate as long as the vapor stream does not contain excessive amounts of solids. 


\section{INTRODUCTION}

The process objective of mild coal gasification is to produce three products with a higher combined value than that of the original coal. The three products are: a low-volatile coke product, a liquid or "oil" product, and a gas product. To meet the economic objective, it is imperative that the three products meet product purity specifications so as to qualify for the right markets. For example, the coke product must meet a maximum allowable limit on volatiles content for use as high-value metallurgical coke. However, the quality of the coke product is not a topic of this study. Rather, the issue here is how to obtain pure oil and gas products, or more specifically how to produce a liquid product free of contaminating solids, and a gas product free of contaminating liquid. This study, therefore, deals with the process downstream of the gasifier. The studied operations include solid separation from a gas or liquid stream and condensation of liquids from a mixture of condensible and noncondensible gas.

All mild coal gasification processes are expected to have a separation problem associated with entrained solids in the vapor stream leaving the gasifier. Fluidized and entrained bed processes are likely to show higher entrainment rates than, for example, less vigorously agitated screw-type gasifiers. However, the fluidized-bed product separation problem is probably only marginally worse than the corresponding mechanically-agitated case. This is because entrainment is already high in mechanically-agitated processes. For example, Rammler (1981) reports a fines content of the composite product oil as high as $7 \mathrm{wt} \%$ from a screw-type gasifier operating on a sub-bituminous coal. For comparison, Ness (1989) reports a fines content of the product oil from a fluidized-bed pilot plant of the order $15 \mathrm{wt} \%$. Particle size distributions of the oil product fines are also given by Ness (1989); the average particle size is reported to be of the order 10-20 $\mu \mathrm{m}$ implying that the two primary cyclones used in the experiments have not performed optimally. (Efficient cyclones should separate essentially all fines with particle sizes greater than $10 \mu \mathrm{m}$ ).

In general, the fluidized-bed processes also have more noncondensible gas present in the gasifier product stream when compared to mechanically-agitated gasifi.srs. This makes condensation more difficult, particularly with regard to the tendency to aerosol formation that is promoted by dilution of the vapor. Again however, the problem already exists for the screw-type gasifiers because of autogeneous noncondensible gas, so that the fluidized-bed situation should only be marginally worse. Also, existing oil refinery techniques are capable of avoiding the aerosol formation problem even with a high dilution of the condensible product by noncondensible gases. However, a pre-requisite for the application of commercially available techniques to the condensation of oil products is the absence of large amounts of contaminating solids; oil refiners process successfully oil vapors diluted by steam arid light hydrocarbon gases, but they generally avoid the additional complication of large quantities of fine solids in the vapor. An example is the 
condensation of the products from a fluid catalytic cracker (FCC) that is usually carried out in a fractionator. The dilution of the oil vapor product by noncondensibles means that the fractionator must be larger and operate at lower temperature than would be the case with no dilution. The problem with contaminating fines is that they become enriched in the bottom product of the fractionator, and plugging of the entire fractionator is known to occur at fairly moderate solids concentrations in the bottom product. Typically, the fines content of the bottom product is kept below 0.2 wt\% (Allen, Jackman and Powell, 1990), implying a solids content of the feed to the fractionator two to three orders of magnitude lower than the fines carryover into the oil of mild coal gasification processes (assuming that cyclones only are used for hot solids separation).

The above arguments lead to the conclusion that most of the entrained solids should be separated from the hot vapor stream upstream of the condensation step. This will not only provide operability of the condensation unit but it will also greatly improve the value of the primary oil product. The goal for the hot solids separation step is to remove the bulk of the entrained solids so as to keep the solids content of the composite oil product below about $250 \mathrm{ppm}$ by weight. This amount of fines would be tolerated by a conventional hydrotreating process for upgrading the coal liquids to transportation fuels (Sullivan, 1978). However, catalyst modifications will be required in conventional hydrotreating processes because of the chemically unfavorable properties of the primary coal liquids. Hydrotreating the coal liquids is considered necessary for the purpose of producing fuels that can be classified as articles of commerce. (The primary coal oil product on the other hand, is not an article of commerce, and the bulk of this product would have to be used as a low-quality fuel by the generating facility itself if it is nut upgraded to saleable products by hydrotreating.)

The solids separation task for the hot gasification product vapor is not easy. The presence of cokable tar components in the vapor product is a significant difficulty when compounded with the additional difficulty of entrained solids too small to be captured by simple cyclones. Apart from the presence of cokable components, the solids separation task is quite similar to the situation for coal-fired gas turbines, such as the pressurized fluidized-bed combustion (PFBC) processes currently under development. The tars present in the mild gasification product gas are expected to deposit coke on any porous ceramic filter medium that would be used in a secondary solids separation device, and this coke will lead to the eventual plugging of the filter. The coking tendency of the vapor, therefore, leads to a requirement for regeneration of the filter mediun by combustion which is significantly more complicated than the simple back-flushing practiced in flue-gas applications. Any operati-. requiring a unit to be alternating between hydrocarbon and oxygen gas environments is operationally complex because of the potential explosion hazard. In addition, the alternating gas environments place special materials requirements on the filter particularly as the filter may experience high temperatures in the regeneration cycle. 
Despite the technical difficulties associated with solids separation from the hot gasification products it is argued in this report that several options are available for successful development of such a component of the mild gasification process. This report first provides a brief overview of similar industrial processes from which valuable lessons can be learned, and then gives an overview of the potential separation techniques with emphasis on their applicability to mild coal gasification. A section is devoted to the issue of condensation of liquids in the presence of noncondensible gas. Finally, the concluding section provides recommendations for further development work. 


\section{PROCESSES WITH SIMILAR PRODUCT SEPARATION PROBLEMS}

\section{Gas Turbines}

Solids separation from pressurized fluidized-bed combustor $(\mathrm{PFBC})$ flue gases is a very active research area because of the desire to minimize erosion of the turbine blades. Podolski et al. (1983) repoit turbine tolerance levels of the order of 10ppm at a particle size of $10 \mu \mathrm{m}$ and $100 \mathrm{ppm}$ at $1 \mu \mathrm{m}$. This is the same order of magnitude as the requirement for mild coal gasification liquids, and consequently, the solids separation requirements are similar for the two processes. PFBC development is moving toward a secondary solids separation step after the cyclones as demonstrated by the DOE-sponsored TIDD project (Durner,1990), an IEA- sponsored project at ABB's test facility in Sweden (Sven Jansson, ABB, private communication), and a pilot-plant project in Finland (Sellakumar et al., 1990). Solid porous ceramics are used as filter media in all three projects, and filter designs of several vendors will be tested.

In comparison to mild coal gasification, PFBC solids separation is carried out at considerably higher temperatures, typically $850-900^{\circ} \mathrm{C}$, and in a flue-gas environment without any cokable tar components present.

\section{Coke Ovens}

The electrostatic precipitator (ESP) is a common solids/aerosol droplet separator in coke oven processes (Roberts and Chamberlin, 1963). Efficiency of collection is reported to be between 95 and $99 \%$, but no information is given for the size of the droplets. It is also reported that the electrical insulators are kept free of tar by purging the insulator compartment with clean gas.

Although the gas env ironment is similar between coke ovens and mild gasification processes, the big difference is the temperature of operation: the coke oven ESP operates near ambient temperature and is therefore not subject to buildup of hard coke on surfaces such as the electrodes, for example. Also, the mostly liquid droplets in the coke oven case result in wet collecting surfaces as opposed to the dry cake that would be the case for hot coal gasification applications. A dry cake of coal char would be expected to become re-entrained because the particles would lose their charge due to their high conductivity.

\section{Eluid-Bed Catalytic Crackers}

The fluid-bed catalytic cracking (FCC) process has a solids separation problem both on the regenerator (combustion) side and on the oil cracking side. The cracking side is of great interest to mild coal gasification because the cracking gas atmosphere is rich in hydrocarbons 
including cokable components, and the entrained catalyst fines are quite small (some below $5 \mu \mathrm{m}$ in particle size). The temperature of the vapor stream is also similar in the two processes, typically around $550^{\circ} \mathrm{C}$. The amount of fines in the vapor stream is however, much less than in the mild coal gasification case. Another difference is that the FCC hydrocarbons are generally lighter, i.e. they have smaller molecular size than the products from coal pyrolysis, but coking is still an issue for FCC vapors. (Even if the coking rate is considerably slower, coke buildup with time would be a considerable operational problem if the FCC included a processing step prone to plugging by coking.)

The typical FCC solids separation scheme is two cyclones in series (and as many as 16 parallel trains in order to keep cyclone size down) coupled with collection of a heavy fractionator bottom product containing all the catalyst fines that escape the cyclones. No references to application of a hot-filtration type secondary solids removal step have been found, probably on account of the coking problem. The traditional method (Allen, Jackman and Powell, 1990) of treating the heavy bottom product was to allow the fines to settle in a large settling or "clarifying" tank. The clarified oil was marketed as marine fuel ("bunker oil"), or as carbon black oil when fines levels of about $500 \mathrm{ppm}$ by weight were tolerated for these products. However, the problem with the settling-tank approach is the disposal of the finesrich sludge that is now classified as hazardous waste in California.

The processing difficulties associated with the FCC oil fines have spurred new developments; recycling of the heavy bottom product to the cracker has been practiced by some refiners (Allen, Jackman and Powell, 1990). The practice is not popular because of catalyst deactivation due to coking of the heavy aromatic oil on the catalyst. A positive feature is that the oil fines apparently become trapped by the coke, and the recycle of fines does not lead to an infinite buildup of entrained solids.

Another interesting approach to the solids/oil separation problem is an electrostatic precipitator developed by Gulf Oil and described by Fritsche and Stegelman (1980). This liquid-phase separator has shown a solids separation efficiency of $96 \%$ of an oil containing $0.45 w t \%$ solids. It has also operated on oils with a fines content as high as $1.8 w t \%$. A drawback of this approach is that a solids-laden slurry is also produced, and this slurry must be disposed of. An option for treating this waste product is to recycle it back to the cracker if this is acceptable with regard to catalyst activity, or to recycle it to the regenerator. In the latter case, the slurry is used for its fuel value only, and the fines are captured by the solids separation devices on the cumbustor side (cyclones and ESP, typically). 


\section{Qil Shale Retorts}

Of the processes studied here, fluidized-bed oil shale retorting is the process that comes closest to mild coal gasification. Both processes involve a pyrolysis product with highly unsaturated and aromatic compounds. The coal oils are generally considered more aromatic than shale oil, but shale oil also contains significant quantities of aromatic compounds with a high tendency to form coke. Wallman, Taylor and Singleton (1990) have determined the coking kinetics of shale oil vapors, and they concluded that pyrolysis vapors form coke even on inert surfaces such as quartz beads. Coking on quartz surfaces occurs even at low oil vapor concentrations. Interestingly, the coking rate on a porous shale-derived solid medium shows a slow-down with coke buildup which was attributed by Wallman et al. (1990) to an increasing mass-transfer resistance. This is favorable but does not eliminate the problem with coke buildup on porous media.

It is argued that the shale pyrolysis vapor results can be extended to apply to coal pyrolysis; coal vapors will also produce coke on all surfaces that come in contact with the vapors. (No coke is found on the pipe walls because they are "cleaned" by particle abrasion. In the interstices of porous media however, there is no abrasion to counter coke buildup.) In order to confirm the predicted coke buildup in mild gasification processes, pilot plants should be operated over extended periods of time. In short-duration experiments a small but steady increase of the "clean" pressure drop across a ceramic filter might not be observed (The clean pressure drop is the pressure drop found right after back-pulsing the filter for cake removal). 


\section{HOT GAS/SOLID SEPARATION TECHNIQUES APPLICABLE TO MILD COAL GASIFICATION}

\section{Cyclones}

A good general overview of cyclones and other solid/gas separations is provided by Svarovski (1981). A more detailed reference for cyclone performance is $\mathrm{Znzz}$ (1989).

The main advantages of cyclones are their simple design and low pressure drop. A disadvantage is the drop-off in cyclone separation efficiency with particle size, and compounding this problem is the condition that the particle cut diameter increases with cyclone size. Dry and La Nauze (1990) present data for standard fluidized-bed boiler cyclones showing the particle $50 \%$ cutdiameter at $5 \mu \mathrm{m}$ for a $0.1 \mathrm{~m}$ cyclone diameter, $20 \mu \mathrm{m}$ for a $1 \mathrm{~m}$ cyclone and $60 \mu \mathrm{m}$ for a $10 \mathrm{~m}$ cyclone. The physical phenomenon producing this effect is simply the curvature of the cyclone wall that in turn determines the centrifugal force acting on the particles (when the inlet gas velocity is held censtant). This cyilone-size effect is also reflected in the conventional design practice of keeping cyclones below $0.9 \mathrm{~m}$ in size and of having a reasonable collection efficiency down to a

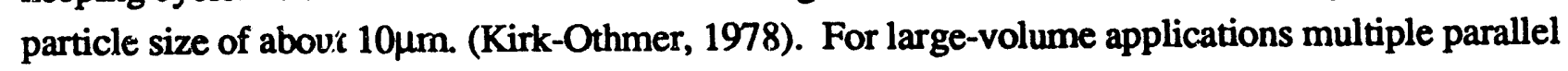
cyclones are thereiore common.

In order to improve the small-particle performance of cyclones a number of special designs have been proposed. Many of these designs involve an additional clean gas feed to the cyclone. The double-vortex cyclone (Svarovski,1981), the aerodyne, the tan-jet, and the air-shield cyclone (Podolski et al., 1983) belong to this category. The important question is how much smaller the particle cut-diameter becomes with these more complex designs, but a certain answer to this question was not found in the literature. Good collection efficiency down to about $4 \mu \mathrm{m}$ can probably be expected from these enhanced designs (Podolski et al.,1983). Interestingly, Iozia and Leith (1989) and (1990) show a 50\% cut-diameter of $4 \mu \mathrm{m}$ in optimized designs of standard cyclones. Hence, it is not unreasonable to assume that with present day cyclone technology efficient collection down to $4 \mu \mathrm{m}$ is possible.

Cyclones with electrostatic agglomeration (Kumar and Helfritch, 1990) or with acoustic enhancement (Rawlins, 1990) are also promising approaches for collection of ultrafine solids.

\section{Barrier Filters}

In most applications of stationary barrier filters the actual filtration of solids occurs on the solids cake that builds up on the filter medium. Trapping of solids inside the filter medium is not desirable because dislodging such solids is difficult. The filter cake on the other hand can be dislodged by a back pulse of gas either on-line or off-line. The filter media for high-temperature applications can be divided into flexible media requiring a support cage such as woven fabrics, and 
rigid media such as porous ceramics strong enough for their own support. Judging from the large volume of papers on rigid porous ceramic filters in the recent literature, hot-gas filtration seems to be tilting toward rigid media at least for flue-gas applications. The reason for this can only be speculated on, but better collection efficiency is a potential explanation; rigid filters, as long as they remain physically intact, provide essentially absolute separation of particles, i.e. their efficiency is essentially $100 \%$. In some woven media, fabric strands may shift so as to open holes that can produce so-called pin-holes in the filter cake. Such pin-holes reduce the filtration efficiency below $100 \%$, and perhaps below $90 \%$. However, this should not be 2 problem for felttype materials.

Representative examples of rigid barrier filter designs are the Westinghouse cross-flow filter (Smeltzer and Bachovchin, 1990), the Asahi-Glass Company reverse-flow candle filter (Oda, 1988) and the Schumacher candle filter (Müller,1987). The most active research with regards to these filters concerns their material of construction. Silicon nitride is a material of interest in may studies (Sawer and Cleveland, 1990), (Van Ackeren and Strumpf, 1990), (Müller, 1987). Apparently, silicon nitride offers enhanced mechanical strength over pure ceramics that have experienced problems with long-term durability. Silicon carbide (carborundum) has also been suggested (Steidel, 1988). However, mechanical strength may not be as severe a problem for mild gasification applications characterized by temperatures around $550^{\circ} \mathrm{C}$ in comparison with the fluegas applications around $900^{\circ} \mathrm{C}$.

A research group at the University of Essen (Weber, 1988) and (Wiggers, Schulz and Weber, 1989) has also paid considerable attention to applications around $400^{\circ} \mathrm{C}$. Among more common filter media they also tested a perforated foil made of nickel on a flue gas at $380^{\circ} \mathrm{C}$ with very good collection results. The foil with a hole size as small as $1 \mu \mathrm{m}$ was fabricated by chemical etching. Unfortunately, stainless steel and other materials of construction that are more appropriate for mild gasification applications cannot be chemically etched in the same way as nickel (which is not appropriate for a sulfur containing gas at $550^{\circ} \mathrm{C}$ ). Sintered stainless steel (a commercial product) on the other hand, is a porous medium and therefore, offers no significant advantage over the ceramic porous media. Hence, a perforated foil suitable for mild gasification applications must be fabricated by special methods.

A rule of thumb regarding the hole size of perforated foils is that the holes must not be larger than 3 times the mass-median diameter of the particles to be collected by the foil (E. Weber, University of Essen, private communication). A consequence of this is that it may be necessary to increase the particle size of the fines by increasing the loading to the filter. Hence, it should not be assumed that cyclone separation efficiency should be maximized in barrier filter applications because such practice would lead to a minimum particle size for the filter. A larger particle size is not only favorable by allowing a larger foil hole size but is also favorable for filter cake 
permeability (High cake permeability means lower cake pressure drop, and consequently longer periods between back-pulsing). This aspect is the reason behind the use of a single cyclone upstream of the barrier filter in many applications such as the TIDD project (Durner, 1990). Electrostatic charging has also been attempted for the purpose of increasing cake permeability with mixed results (Schmidt and Löffler, 1990).

\section{Moving Granular Beds}

In early applications of granular beds, the bed simply served as a filter medium supporting the cake much like the barrier filters discussed above. Recent applications of granular beds involve deep, in-bed filtration where the fine particles are captured by the larger bed particles through electrostatic or van der Waals forces. The theory of in-bed deposition of fine particles is quite complex, and will not be reviewed here. An excellent account of the physics of granular beds is provided by Tien (1989).

Combustion Power Company has been involved in the development of granular beds for many years. Their early emphasis was on a granular bed with electrostatic enhancement (Grace, Guillory and Placer, 1979). This design also used louvered screens. Apparently, the screens showed fouling even in flue-gas applications (J. C. Haas, Combustion Power Company, private communication) producing a shift in emphasis to the current screenless bed design without electrostatic enhancement (Wilson and Haas, 1989). This latter design has also been tested by an independent group (Zakkay et al., 1989). This group reports particle collection efficiencies between 98 and $99 \%$ obtained with $2 \mathrm{~mm}$ or $3 \mathrm{~mm}$ bed particles, and with gas velocities of the order $50 \%$ of minimum fluidization velocity of the bed. This is very impressive performance especially when considering that the separated flue-gas fines were quite small: $20 \%$ below $4 \mu \mathrm{m}$. The disadvantage of the granular bed is of course, the complexity of the regeneration system including a lift pipe, bed-particle/fines disengager and other equipment.

The inherent regeneration of the bed material in granular beds makes this solids separation technique particularly attractive to mild coal gasification applications. An example of interest in granular beds is the work of Kamei et al. (1989) who consider the application of a moving granular bed to a high-temperature coal gasifier. This application may also be an indication that some hightemperature gasification processes have coking problems similar to mild coal gasification due to the presence of small quantities of tar compounds in the product gas. 


\section{CONDENSATION OF CONDENSIBLE-NONCONDENSIBLE GAS MIXTURES}

\section{Thermodynamics}

Fig. 1 shows a typical solids separation/liquid condensation process for mild coal gasification. After secondary solids separation in a barrier filter the vapors enter near the bottom of a tray tower where condensation and fractionation occur. Heavy oil is condensed from the vapor by contacting down-flowing heavy liquid over so-called shed trays that allow some solids loading of liquid. The bottom part of the fractionator could be a separate vessel, and the vapor/liquid contaci could also be in the form of a spray or a wetted film on the walls. A separate vessel would be advantageous from an operations point of view if plugging due to high solids loadings is likely. Otherwise, the combination of heavy and light oil condensation in one vessel is favorable. It should be noted that the product names in Fig. 1 reflect boiling distributions rather than saleable hydrocarbon products.

The bottom product called "cycle oil" in Fig.1 is an undesirable product because of its unfavorable chemical and physical properties, and its potential solids content. Recycle of this stream to extinction would be a significant process advantage because this low-quality product would then be eliminated. The recycle stream would be converted into coke (containing all the solids), lighter oils and noncondensible gas.

Condensation of the heavy oil in the bottom of the fractionator has been studied by means of thermodynamic vapor/liquid equilibrium calculations. For these calculations a boiling point distribution for the total condensible hydrocarbon product was assumed. The assumed boiling point curse is shown in Fig.2. This curve will, of course, vary with gasifier processing conditions, particularly if the heavy bottom product is recycled. However, qualitative observations concerning the effect of noncondensible diluents can be made despite this uncertainty.

Fig. 3 shows the calculated dew point as a function of the amount of diluent on the basis of the assumed boiling point curve of Fig.2. Even without diluent, the dew point is significantly lower than the boiling point of the heaviest oil component. The reason for this is the reduction in heavy oil vapor pressure due to dilution with lighter oil components. This effect continues when light gas diluent is mixed in. Coal pyrolysis produces significant amounts of noncondensible hydrocarbons, $\mathrm{CO}_{2}$ and water, and a typical level of these gasification products is shown as "autogeneous atmosphere" in Fig.3. In addition to this gas, fluidized and entrained bed gasifiers use recycle gas that further increase the diluent/oil ratio in the condensation step. Fig. 3 shows how the dew point responds to this dilution. 
The heavy oil condensation in the bottom of the fractionator will generally be carried out at a temperature lower than the dew point (Otherwise the fractionator will have no bottom product). Fig. 4 shows the effect of the condensation temperature on the amount of oil condensed for a specific diluent/oil ratio typical of fluidized-bed gasification. Over the temperature range studied $\left(385-285^{\circ} \mathrm{C}\right.$ ) the condensed fraction increases approximately linearly from $0 \%$ to $40 \%$. The temperatsys of the bottom of the fractionator (which is controlled by the cooling of the heavy oil recycle to the fractionator, Fig. 1 ) is therefore, a handle on the amount of bottom product. If solids are present in this product it is desirable to operate the bottom relatively hot so as to contaminate only a small fraction of the liquid product. However, viscosity of the liquid and the onset of coking reactions in the liquid are factors that limit the heavy oil condensation temperature. Oil refinery practice is to keep the bottom temperature below $350^{\circ} \mathrm{C}$ which in the case at hand translates to about $15 \%$ of the total liquid product being prociweed as fractionator bottom product.

Condensation of the lighter oils is relatively straightforward, and can be carried out so as to produce several side-draw products as shown in Fig.1. The lightest component called "naphtha" in Fig. 1 is condensed together with the water in the overhead condenser. The temperature in this condenser is typically near ambient temperature. The n..phtha is separated from the water by phase separation. In the overhead separation vessel the noncondensible gases are also separated from the liquids, and part of the gas is recycled as fluidization gas to the gasifier.

\section{Aerosol Formation}

Aerosol, or oil mist formation has been reported for several mild coal gasification installations. This phenomenon therefore warrunts some comment here.

A condenser aerosol is a symptom of droplet condensation as opposed to the desired "film" condensation which may occur either on a cooled equipment surface, or on a cooled liquid surface. An example of a liquid surface is the vapor/liquid contact between rising vapor bubbles on a tray of the fractionator. Nucleation which is formation of the first small of "packets" of liquid requires a high degree of supersaturation. This is because a curved liquid surface has a higher vapor pressure than a planar surface, and the smaller the curvature, the higher the equilibrium vapor pressure. Droplets are thermodynamically stable only if the oil vapor pressure around them is greater than their own equilibrium vapor pressure. Since nucleation droplets are very small they have a high equilibrium vapor pressure, and consequently, a low temperature, i.e. high supersaturation, is necessary for their formation. Thus, in order to avoid aerosols by thermodynamic means one should avoid cooling the vapors rapidly by contact with very cold surfaces (much below the dew point of the mixture). Instead, the vapors should be cooled only moderately below their dew point so as to avoid a high degree of supersaturation. 
Nucleation on entrained fines occurs at lower supersaturation levels than in the absence of fines because the droplets can start out at a larger, and more stable size. Hence, droplet condensation is more difficult to avoid by limiting the degree of supersaturation when entrained fines are present. A compensating feature is that solid-induced aerosols are generally larger in size, and are therefore easier to coalesce into a liquid film.

The presence of a noncondensible diluent is also believed to be unfavorable for film condensation but explanation of this phenomenon requires some analysis. As discussed above, the presence of diluents has consequences for the thermodynamic phase equilibrium resulting in lower operating temperatures for the condensation process. This should not affect the degree of supersaturation, and therefore, not the thermodynamic tendency to aerosol formatioli either. However, there is a kinetic effect from diluents that impedes film condensation. This kinetic efiect is the mass transfer of oil vapor molecules from the bulk gas to the condensed film surface. A diluent lengthens this mass-transfer distance and therefore, slows it down. This in turn, leaves more time for the competing mechanism of droplet nucleation. To compensate for this effect, the vapor/liquid contact must be particularly good when diluents are present. Good contact means that the vapor must be well distributed across the cooling surfaces. Vapor bubbles rising through a cooling liquid is a case of distributed contact because the mass-transfer distance is only the distance to the bubble/liquid interface. A consequence of the distributed contact is that the effect of diluents is not very important in vapor/liquid tray or packed columns. In heat exchangers on the other hand, the mass transfer distance can easily be an order of magnitude larger than in vapor/liquid tray columns, and aerosol problems are likely to occur in the heat exchanger applications that are common for pilot plants. 


\section{CONCLUSIONS AND RECOMMENDATIONS FOR FUTURE WORK}

Condensation of the oil product from the primary mild coal gasification product stream can be carried out using existing commercial techniques, such as vapor/liquid tray columns, packed columns, and for small-scale applications, wetted-wall columns, spray columns, and venturi-scrubbers. The important condition for the condensation step regardless of the detriled design is good vapor/liquid contact which requires recirculation of cooled product oil. For fullscale plants, a fractionator with a light naphtha reflux to the top of the column and another oil recycle loop near the bottom of the column is the recommended solution. The product vapor stream enters the fractionator near the bottom and contacts the downflowing oil from the bottom oil recirculation. The bottom trays should have a design allowing a moderate level of solids loading. Any entering solids will be carried to the bottom product of the fractionator.

Pilot plants may' have, design constraints on the vapor/liquid contacting pattern producing inadequate contact with the result of aerosol formation. In this case, cyclones coupled with a demister (solid surface for uroplet coalescence) can be used to collect the aerosol. Coke-oven experience shows that electrostatic precipitators can also be used to collect aerosols even when the aerosols contain solids. In commercial-scale operations however, aerosol formation can and should be avoided.

Processing schemes that allow si nificant quantities of ultrafine solids into the oil product are troublesome because removal of ultrafines from a hydrocarbon liquid is a difficult and expensive proposition. This is shown by the commercial practice for solids containing heavy oil from fluid catalytic cracking: most refiners consider this stream a waste product instead of a feedstock for saleable transportation fuels (Allen, Jackman and Powell 1990). Even with expensive liquid/solid separators the solids only become concentrated in a smallervolume waste stream.

A mild coal gasification process option for a solids containing heavy oil product is to coke it in the gasifier. Coking part of the oil will ideally trap the solids in the coke, and provide some lighter oil components by cracking. Process questions such as efficiency of the solids capture by the coke, properties of the coke formed and properties of the cracked oil products are candidates for future laboratory studies. If most of the recycle oil yields coke of low quality (which is expected at high solids concentrations) this process option has limited merit.

Efficient solids removal upstream of the condensation step is a very desirable feature of any mild coal gasification process. The coking tendency of the tar vapors makes hot solids separation from gasifier products significantly more difficult than the corresponding solids separation problem for flue gas applications. Coke build up on the filter medium, even at a slow rate, makes regeneration of the filter medium by combustion necessary. This is 
operationally difficult, and places stringent requirements on the materials of construction. High-temperature gasification of coal may produce enough high-molecular tar compounds that coking is an issue even in some high-temperature gasification processes. However, there is limited experience with long-term hot gas filtration even for high-temperature gasification. Based on oil shale pyrolysis studies by the author, coking of filter media is concluded to be a problem for mild coal gasification processes. A coking study of coal pyrolysis vapors over typical filter media is proposed for FY 92.

A consequence of the coking tendency of the mild gasifier products is that hot solids separators should ideally be as "open" in design as possible. The narrow gas passages found in, for example, porous ceramic or sintered steel media are unsuitable because these passages will plug up and be difficult to regenerate even hy combustion once they are plugged by coke. Hence, cyclones and electrostatic precipitators are at first glance favorable. However, electrostatic precipitators are ruled out on account of the problem associated with maintaining a high-voltage field between electrodes that are subject to coke deposits. The low resistivity of the solids is another problem. In contrast to ESPs, cyclones have more favorable properties; cyclones do not plug with coke because particle abrasion of surfaces eliminates coke buildup. A disadvantage is the low collertion efficiency for fine particle; standard cyclones perform well 'down to approximately $10 \mu \mathrm{m}$, high-efficiency cyclones can be expected to perform well down to about $4 \mu \mathrm{m}$. A compounding problem is that the cyclone itself produces attrition and generation of ultrafine materiel (Zenz, 1971). In the author's opinion, a particle cut-diameter of $4 \mu \mathrm{m}$ will be inadequate for most mild coal gasification processes. Consequently, a more efficient cyclone must be developed if cyclones are also to serve as the secondary particulate removal devices (cyclones are, of course, the natural choice for primary particulate removal).

The prime candidates for secondary particulate removal from mild gasification vapors are stationary barrier filters and moving granular beds. The moving beds are attractive because they inherently provide regeneration of the coked bed material; the air-blown lift pipe that is used for removal of the captured fines will also burn off the coke that is deposited on the bed material during the contact with the gasifier vapors. To further compensate for their complexity, the granular beds offer the opportunity of oil upgrading by purposely coking and cracking the oil vapors. A candidate for further work in this regard is to study catalytically active bed materials such as zeolites in a bench-scale mild gasifier. The process advantage of catalytic cracking of the coal oils is a lighter product oil more suitable for subsequent hydrotreating.

The development objective for the proposed barrier filters is to find a filter medium that provides both good separation efficiency, good coke resistance and easy regeneration (because coking probably cannot be totally eliminated). An ideal material would have zero coking 
tendency, but a more realistic goal is to find a filter medium with low coking tendency. In this regard previous experience (Albright and Crynes, 1976) with coking of exotic materials such as titanium, tantalum and tungsten in light hydrocarbon cracking provides guidance. The coking tendency of potential filter materials will be studied in the continuous bench-scale unit. The second design objective of easy regeneration is met by a perforated foil design, i.e. a thin sheet with very small holes, because the surface area subject to coking is comparatively small (compared to porous media) and the coked foil should be relatively easy to regenerate by burning off the easily accessible coke. There is also a chance that the small amounts of solids that penetrate the foil after back-flushing the cake will keep the perforations open by mechanical abrasion. The first filter candidate to be tested is a 0.002 -inch thick stainless steel foil with $10 \mu \mathrm{m}$ perforations made by a laser-drilling technique.

To date, the best candidate for hot solids removal from coal pyrolysis vapors is a candle filter made of a perforated foil. The material of construction remains to be determined by longterm testing in the continuous bench-scale apparatus. The goal is to find a material of low coking tendency in the chemically difficult environment of mild coal gasification vapors. After laboratory development of an appropriate filter for mild coal gasification, it would be natural to design a filter for field demonstration on a pilot plant, followed by application to a $1000 \mathrm{lb} / \mathrm{hr}$ 'plant. 


\section{REFERENCES}

Albright, L.F., Crynes, B.L. (Editors) Industrial and Laboratory Pyrolyses, ACS Symp.Ser. 62, American Chemical Society, Washington D.C., 1976.

Allen, P., Jackman, A., Powell, R. Petroleum Refining Industry Waste Audit, Report to the Department of Health Services, State of California, University of California, Davis, May 1990.

Dry, R.J., LaNause, R.D. "Combustion in Fluidized Beds", Chem. Eng. Progr., Jul 1990, 31-47.

Durner, M.W. "PFBC Hot Gas Cleanup Facility", Proc. of the 7th Annual Coal-Fuel Heat Engines and Gas Stream Cleanup Systems Contractors Review Meeting, DOE/METC, Morgantown, 1990.

Fritsche, G.R., Stegelman, A.F. "Electrostutic Catalyst Separator Upgrades FCC Bottoms", Oil and Gas J., Oct 1980, 55-59.

Grace, D.S., Guillory, J.L., Placer, F.M. "Electrostatic Enhancement of Moving-Bed Granular Filtration", 2nd Symp. on the Transfer and Utilization of Particulate Control Technology, Denver, July 23-27, 1979.

Iozia, D.L., Leith, D. "Cyclone Optimization", Filtration and Separation, 1989, 271-274.

Iozia, D.L., Leith, D. "The Logistic Function and Cyclone Fractional Efficiency", Aerosol Sci. and Techn. 12, 1990, 598-606.

.amei, K., Ihara, S., Habata, O., Kodama, K. "Modeling of Hot Gas Dust Collector for integrated Coal Gasification Combined Cycle Power Plant", Proc. of the 1989 Intern. Conf. on Coal Science, IEA, Tokyo, 1989.

Kirk-Othmer Encyclopedia of Chemical Technology, Wiley, N.Y., 1978.

Kumar, K.S., Helfritch, D.J. "Integrated Low Emissions Control for Direct Coal-Fueled Turbines - Electrostatic Agglomeration", Proc. of the 7th Annual Coal-Fuel Heat Engines and Gas Stream Cleanup Systems Contractors Review Meeting, DOE/METC, Morgantown, 1990.

Müller, M. "Innovative Heissgasfiltration bei Temperaturen bis $1000^{\circ} \mathrm{C}$ und Drucken bis 50bar", Chemie-Technik 16, 1987, 29-33.

Ness, R.O. Development of an Advanced Continuous Mild Gasification Process for the Production of Co-Products, Final Technical Report to DOE/METC for the period Feb 1988 Mar 1989 under Contract DE-AC21-87MC24267, Univ. of North Dakota, Grand Forks, Dec 1989.

Oda, N. "New Ceramic Tube Filter Technology for Hot Gas Cleaning", 1988 Seminar on Fluidized-Bed Combustion Technology for Utility Applications, EPRI, Palo Alto, 1988.

Podolski, W.F., Miller, S.A., Vogel, G.J., Gehl, S.M., Hanway, J.E., Henry, R.F., Smyk, E.B., Swift, W.M., Parker, K.M., Graves, R.L., Griffin, F.P., Lackey, M.E. Pressurized Fluidized Bed Combustion Technology, Noyes Data Corporation, New Jersey, 1983. 
Rammler, R.W. "Low-Investment Carbonization Process for Coal Makes Liquid, Gas and Boiler Fuel", Oil and Gas J. , Nov 1981, 291-305.

Rawlins, D.C. "Subpilot-Scale Testing of Acoustically Enchanced Cyclone Collectors for Pressurized Fluidized-Bed Combustors", Proc. of the 7th Annual Coal-Fuel Heat Engines and Gas Stream Cleanup Systems Contractors Review Meeting, DOE/METC, Morgantown, 1990.

Roberts, L.M., Chamerlin, R.L. "Detarring of Coke Oven Gas by Electrostatic Precipitators in the United States", Dechema Monogr. 48, 1963, 306-316.

Sawer, J., Cleveland, J. "Cordierite Silicon Nitride Filters", Proc. of the 7th Annual Coal-Fuel Heat Engines and Gas Stream Cleanup Systems Contractors Review Meeting, DOE/METC, Morgantown, 1990.

Schmidt, E., Löffler, F. Untersuchungen zum Einfluss elektrostaticher Effekte auf Partikelabscheidung, Druckverlust und Abreinigungsverhalten periodisch regenerierten Fasernschichtfiltern, NTIS Report DE90 767232, Univärsitet Karlsruhe, 1990.

Sellakumar, K.M., Isaksson, J., Provol, S.J. "High-Pressure High-Temperature Gas Cleaning", Proc. of the 1991 Intern. Conf. on Fluidized Bed Combustion, ASME, Montreal, Apr 1991, 1087-1094.

Smeltzer, E.E., Bachovchin, D.M. "Long Term Durability Testing Of Ceramic Cross Flow Filter", Proc. of the 10th Annual Gasification and Gas Stream Cleanup Systems Contractors Review Meeting, DOE/METC, Morgantown, 1990.

Streidel, D. "Heisse Gase-Trocken Entstauben", Umwelt 11-12, 1988, 582-584.

Sullivan, R.F. Refining and Upgrading of Synfuels from Coal and Oil Shales by Advanced Catalytic Processes, Report to DOE under Contract EF-76-C-01-2315, Chevron Research Company, Richmond, California, Apr 1978.

Svarovski, L. Solid Gas Separation, Elsevier, Amsterdam, 1981.

Tien, C. Granular Filtration of Aerosols and Hydrosols, Butterworths, Boston, 1989.

Van Ackeren, J., Strumf, H. "Membrane Filter Technology, RSBN Crossflow Filters", Proc. of the 7th Annual Coal-Fuel Heat Engines and Gas Stream Cleanup Systems Contractors Review Meeting, DOE/METC, Morgantown, 1990.

Wallman, P.H., Taylor, R.W., Singleton, M.F. "Shale Oil Cracking and Coking Kinctics" Proc. of the 4th Annual Oil Shale and Tar Sands Contractors Review Meeting, DOE/METC, Morgantown, 1990, 113-123.

Weber, E. "Rauchgasentstaubung: Stand der Technik und Entwicklungstendenzen bei der Hochtemperatur-Entstaubung", VDI Berichte Nr 690, 1988, 135-156.

Wiggers, H., Schulz, R., Weber, E. "Hot Gas Cleaning - Status and Development", 1989 Conference on Technologies for Producing Electricity in the 21st Century, EPRI, Palo Alto, 1988.

Wilson, K.B., Haas, J.C. Performance Analysis of a Screenless (Counter-Current) Granular Bed Filter on a Subpilot-Scale PFBC, Volume II, DOE/MC/21335-2823, 1989. 
PHWallman: Separation of Products...

Zakkay, V., Gbordzoe, E.A.M., Radhakrishnan, R., Sellakumar, K.M., Patel, J., Kasinathan, R., Haas, W.J., Eckels, D.E. "Particulate and Alkali Capture from PFBC Flue Gas Utilizing. Granular Bed Filter", Comb. Sci. and Teck. 68, 1989, 113-130.

Zenz, F.A. "Find Attrition in Fluid Beds", Hydrocarbon Processing, Feb 1971, 103-105.

Zenz, F.A. Fiuidization and Fluid-Particle Systems, Vol II, Pemm-Corp Publications, Nelsonville, N.Y., 1989. 


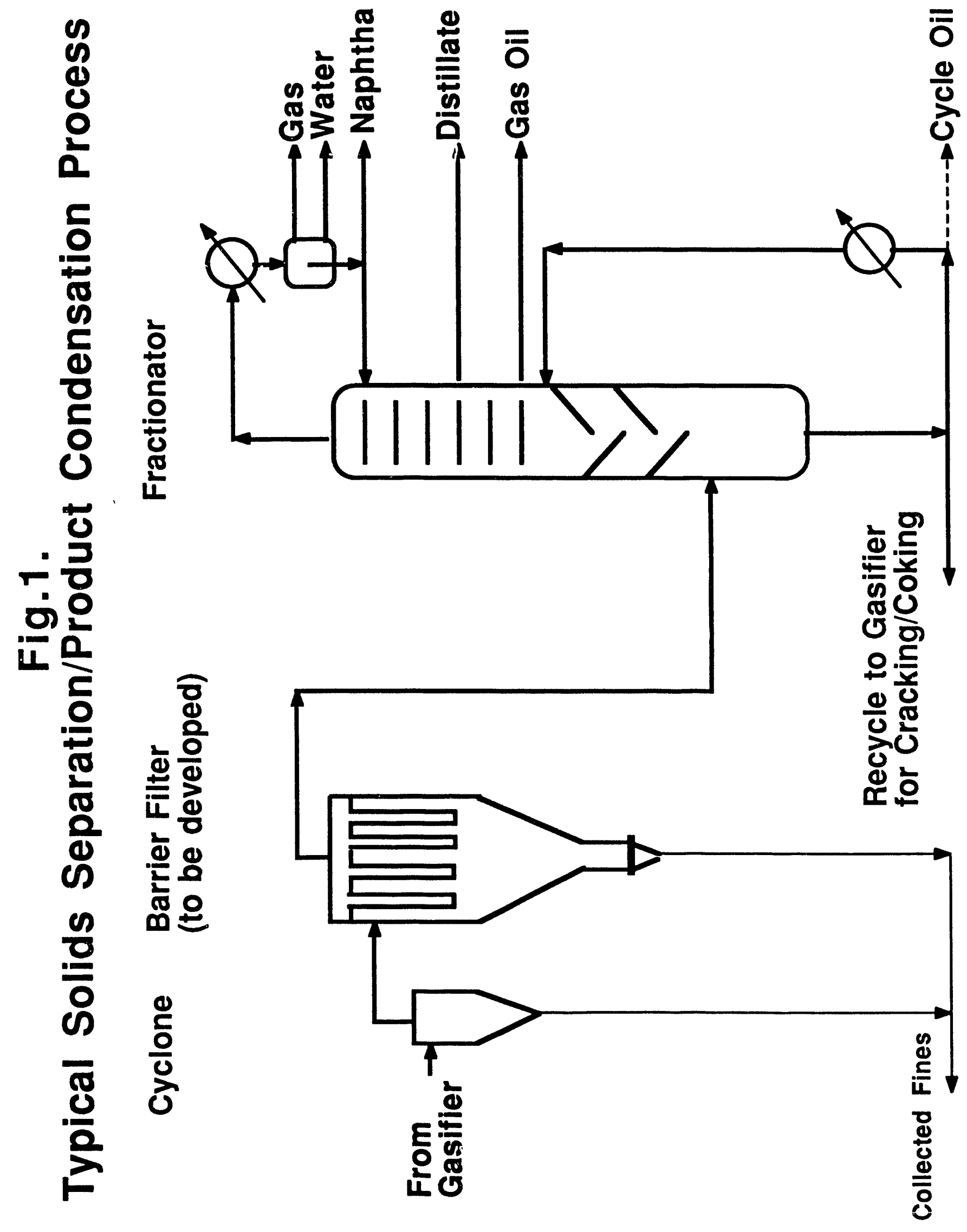


Fig.2. Assumed Boiling Point Curve for Whole Oil

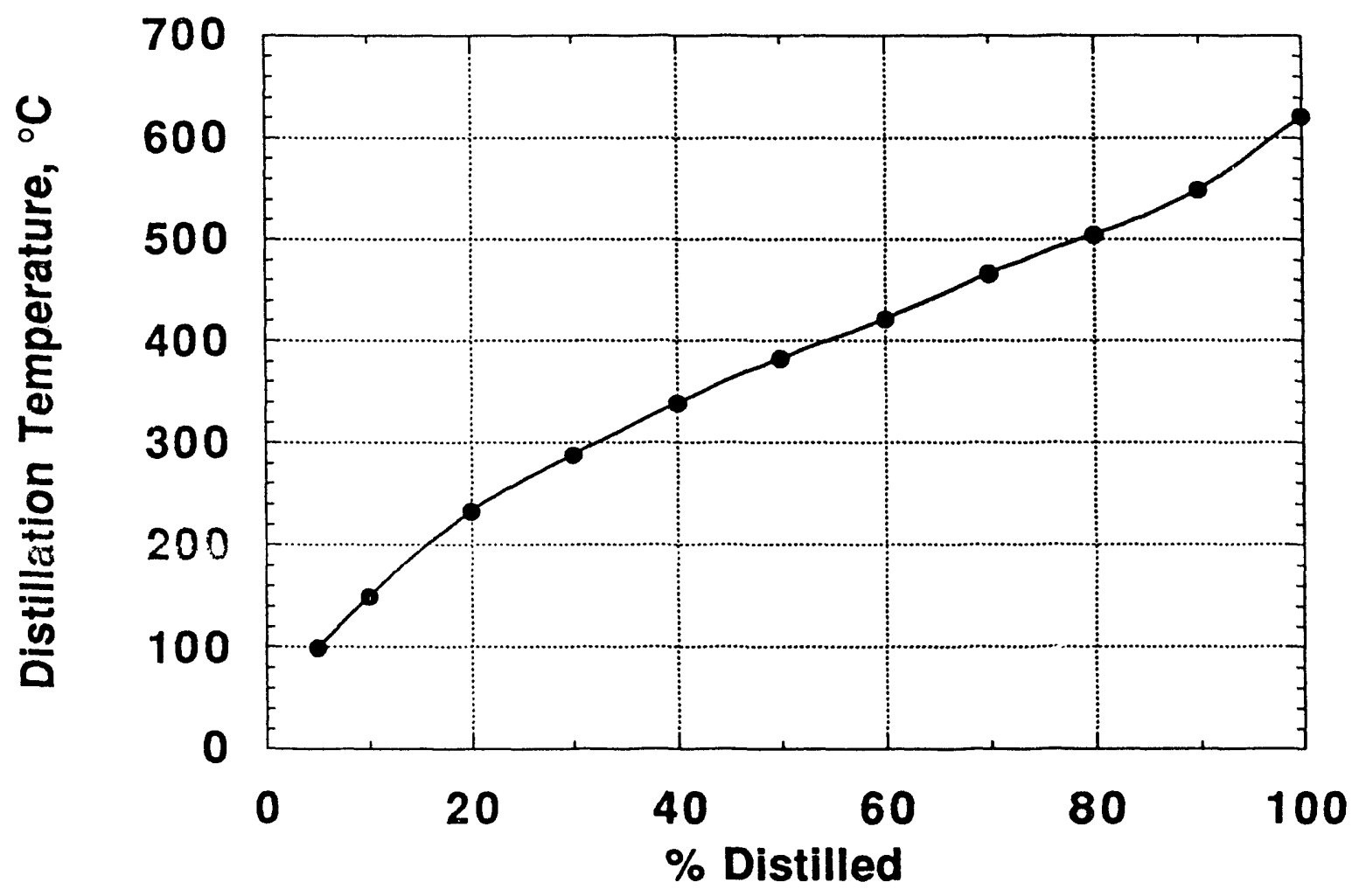


Fig.3. Effect of Noncondensible Diluent on Oil Dew Point Oil: $20 \%$ bp $>500^{\circ} \mathrm{C}$, Avg.MW=300 g/mol

Diluent: $M W=25 \mathrm{~g} / \mathrm{mol}$

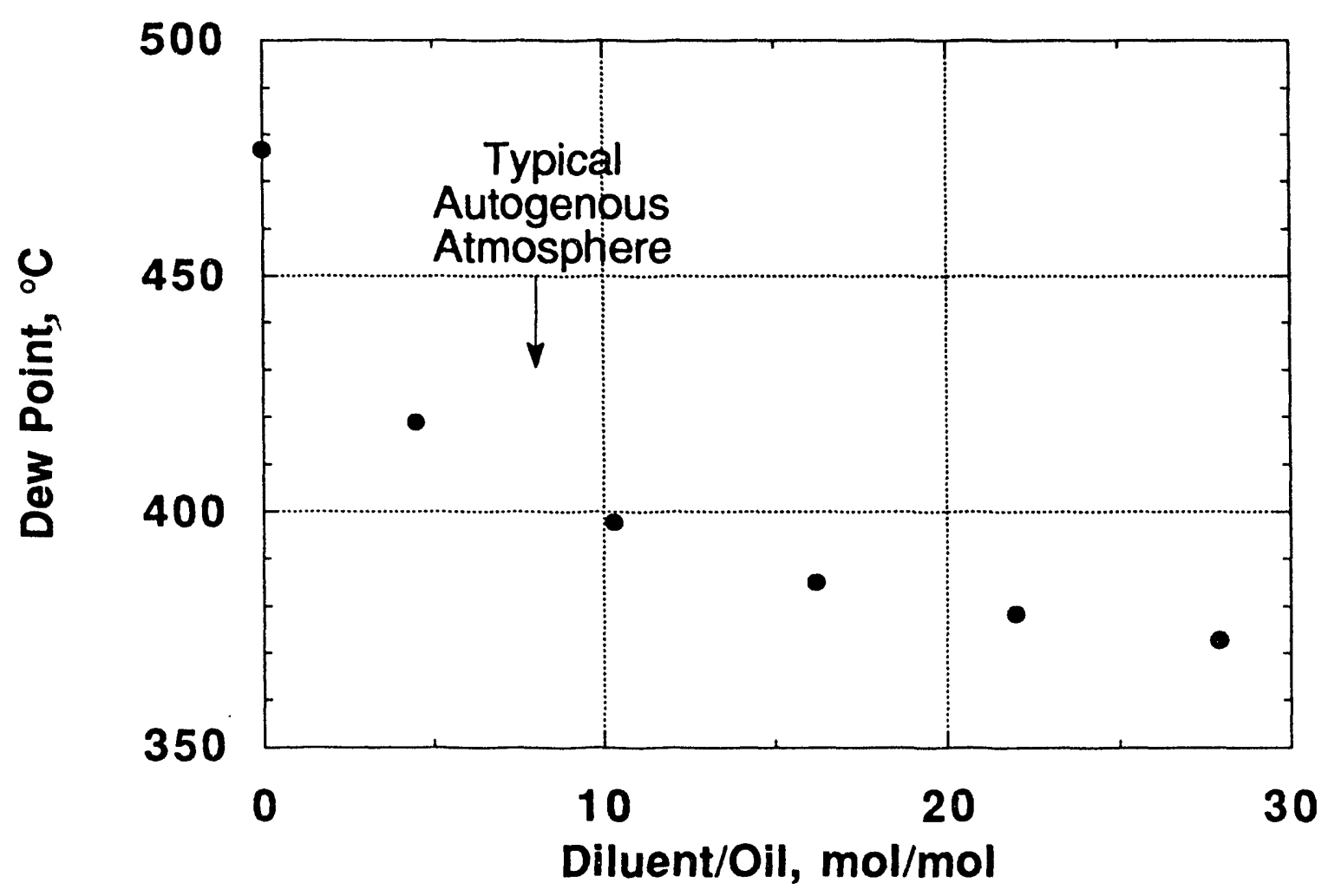


Fig.4. Effect of Temperature on Amount of Oil Condensed Oil: $20 \%$ bp $>500^{\circ} \mathrm{C}$, Avg. $M W=300 \mathrm{~g} / \mathrm{mol}$

Diluent: $M W=25 \mathrm{~g} / \mathrm{mol}$

Diluent/Oil=16 $\mathrm{mol} / \mathrm{mol}$

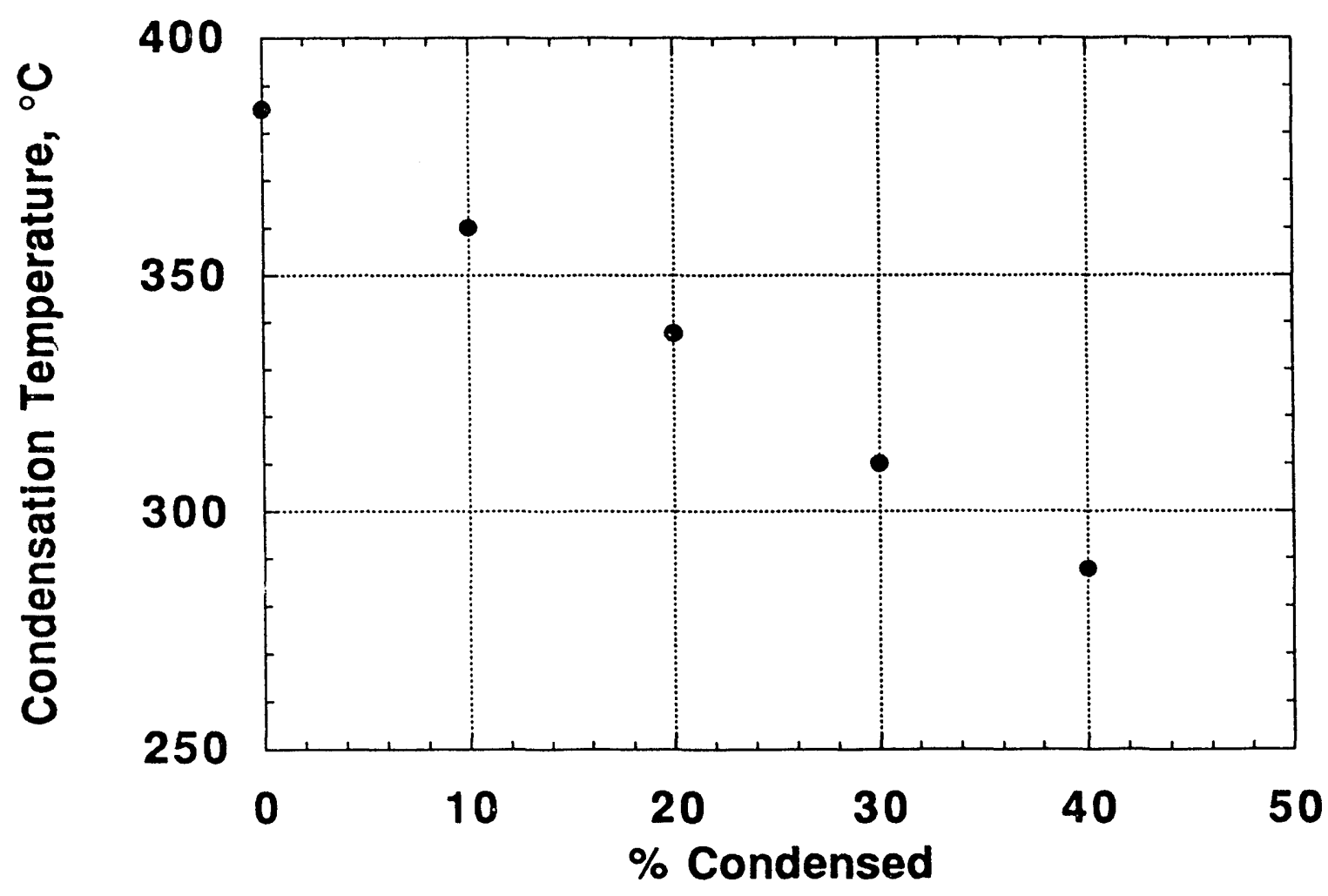



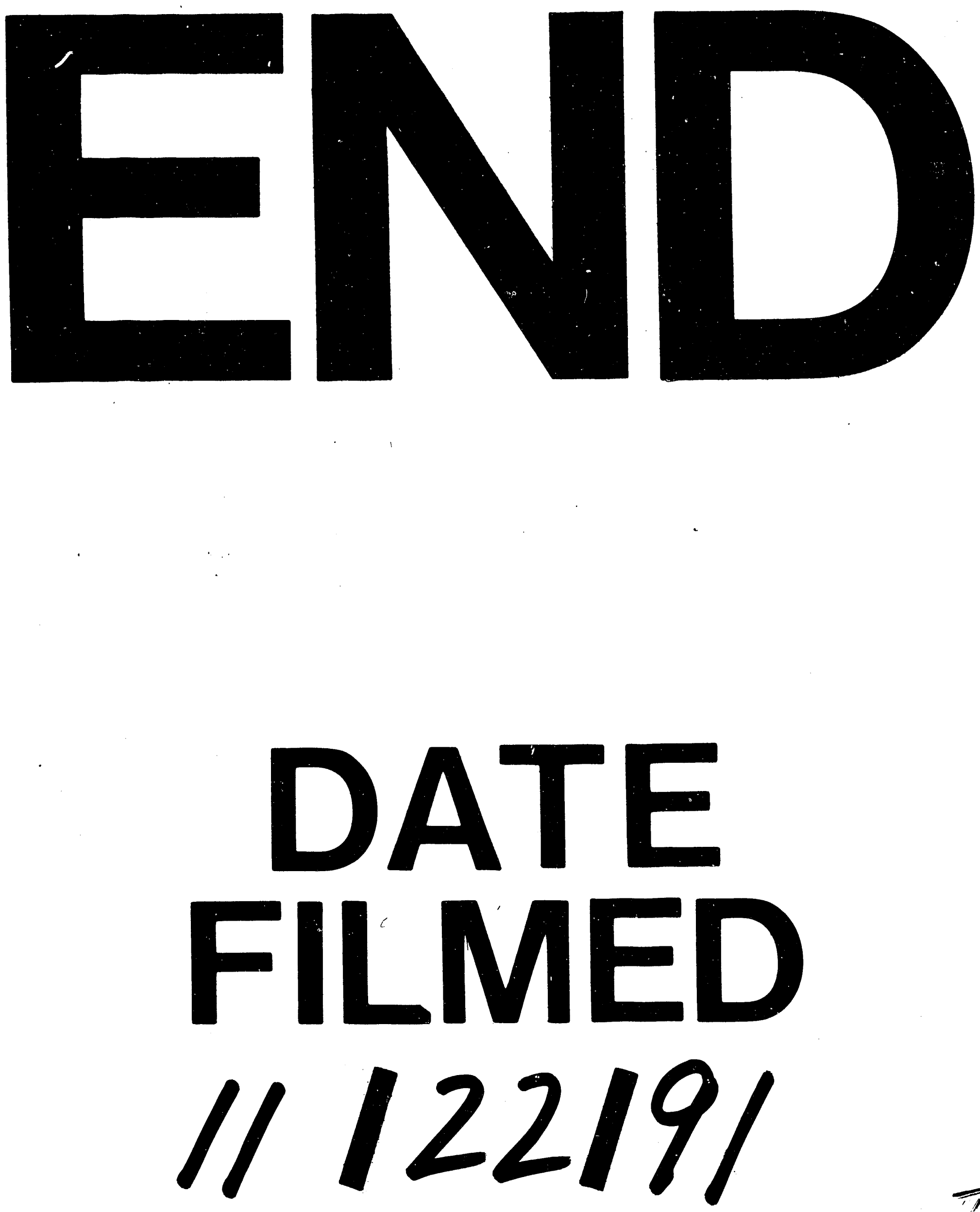